\title{
THE GEOGRAPHICAL DISTRIBUTION OF THE GENUS SIMULIUM LATREILLE IN THE ORIENTAL AND AUSTRALASIAN REGIONS
}

\author{
HIROYUKI TAKAOKA \\ Received March 7, 1996/Accepted April 24, 1996
}

\begin{abstract}
The geographical distributions of the genus Simulium Latreille s.l. in the Oriental and Australasian Regions were mapped. The patterns of distribution were examined at the subgenus and speciesgroup levels. Among the 11 subgenera recorded in these regions, five (Byssodon, Eusimulium, Montisimulium, Nevermannia and Simulium s.str.) were essentially Palaearctic, apparently penetrating to varying extents from the north to the Oriental Region and two of which were further extending their eastward ranges up to the Australasian Region; while the other six subgenera (Gomphostilbia, Hebridosimulium, Himalayum, Inseliellum, Morops and Wallacellum) were nearly endemic to the Oriental or Australasian Regions or both. All the endemic subgenera, except Himalayum, had their own center of development and distribution on the islands. Eight of 12 species-groups of Simulium s.str. were mostly confined to the Oriental Region, and five of which demonstrated a definite insular pattern in their distribution. The probable dispersal routes were inferred for several species-groups of the subgenera Nevermannia and Simulium s.str. The Simulium faunae of the Philippines, Sulawesi and the Maluku Islands present a mixture of the Oriental and Australasian elements but the faunal break is likely to be seen on both sides of the Weber's Line.
\end{abstract}

\section{INTRODUCTION}

Black flies (Diptera: Simuliidae) are one of the most important groups among the blood-sucking insects. This family includes serious pests of man and animals in many countries. Some species transmit several pathogens, such as filarioid nematodes of the genus Onchocerca to man and cattle. The family is widely distributed in all zoogeographical regions, being found almost anywhere if there is running water suitable as a habitat of the immature stages.

The Simuliidae in the Oriental Region were so far classified by Crosskey (1967, 1988) and Datta (1983), and their faunal feature was briefly described by Crosskey (1990). Recently we revised the species-groups within the two subgenera, Gomphostilbia Enderlein and Simulium Latreille s.str., of the genus Simulium Latreille s.l. (Takaoka and Davies, 1996) and provided a checklist of the Simuliidae in the Oriental Region (Takaoka and Davies, 1995), in which all the 246 species, but one tentatively assigned to the genus Sulcicnephia Rubtsov, were placed in the 11 subgenera of the genus Simulium s.l. and under three major subgenera were further classified into several species-groups.

The Oriental Region consists of two types of lands, continental (India, Indochina and south China) and insular (Philippines and Indonesia), and climatologically belongs for the most part to tropical and subtropical zones. This region is generally delimited on the north by the Himalayan mountain range and the Yangtse River in south China, on the west by the dry zone of Kashmir, and on the east by the so-called Wallace's Line or Weber's Line, both of which have been long reputed to separate it from the Australasian Region (Fig. 1). Gressitt $(1956,1961)$ analysing geographical distribution patterns of several insect families revealed that the Oriental elements stretched eastwardly far beyond these nominate lines, and included vast ranges of oceanic islands including New Guinea in the Oriental Region. $\mathrm{He}$ also discussed the faunal origins and affinities of most oceanic islands (Gressitt, 1961).

The distributional features of the genus Austrosimulium Smart in Australia and New Zealand, and the subgenus Inseliellum Rubtsov in Polynesia were already shown by Dumbleton (1963) and Craig (1983) respectively. However, no such attempts have been

Division of Medical Zoology, Oita Medical University, Hazama, Oita 879-55, Japan 


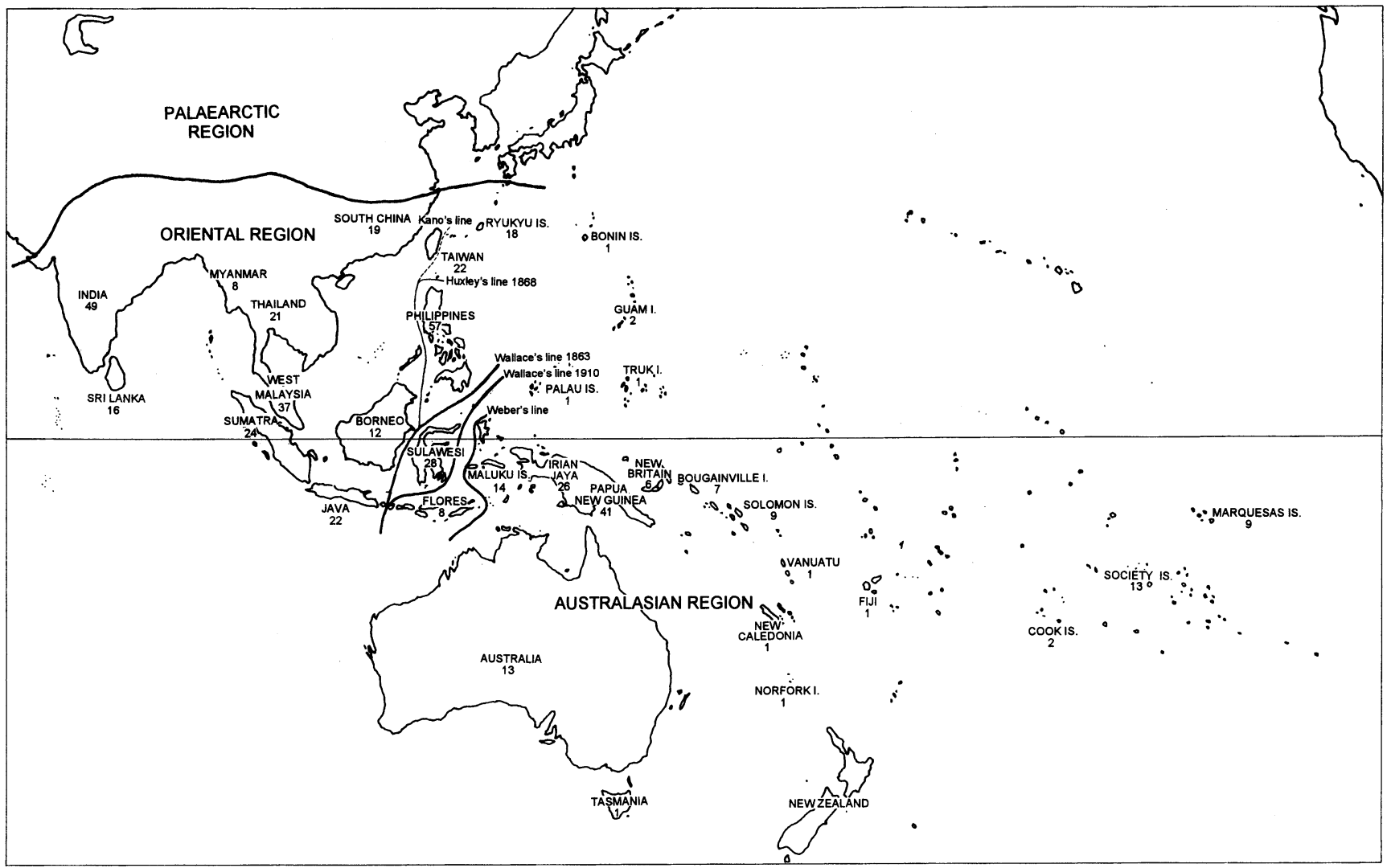

Figure 1 Map of the Oriental and Australasian Regions showing several zoogeographic borderlines. Numeral below locality name indicates the number of species of the genus Simulium s.l. so far found. Horizontal line indicates ecuator.

done in the Oriental Region, mainly due to the lack of the faunistic investigations, especially in the eastern part of Indonesia including Sulawesi Island (Celebes), the Maluku Islands (Moluccas), Irian Jaya and the Lesser Sunda Islands. In this paper the geographical distributions of the genus Simulium s.l. in the Oriental and Australasian Regions were outlined and drawn at subgenus and species-group levels, on the basis of the published and unpublished data including one recently obtained from our faunistic surveys in Indonesia and Peninsular Malaysia. Main information sources were Takaoka and Davies (1995) for the Oriental Region, Crosskey (1967, 1989), Takaoka and Suzuki (1995), Takaoka (1995) for the Australasian Region, Crosskey (1988) for both regions, and Craig and Craig (1986), Craig (1987) and Craig et al. (1995) for Polynesia.

\section{DISTRIBUTIONS OF TRIBES AND GENERA}

(Fig. 2)

The family Simuliidae was divided into two subfamilies, i.e., Parasimuliinae and Simuliinae, of which the latter was further divided into two tribes, i.e.,
Prosimuliini and Simuliini (Crosskey, 1988). The majority of black fly species in this area were placed in the worldwide genus Simulium s.l. of the tribe Simuliini. This genus occurs in most areas of the Oriental and Australasian Regions and extends on the south up to Tasmania Island, on the northeast to the Micronesian Islands, and on the east as far as the Marquesas Islands. Another genus Austrosimulium is confined to south and east Australia and New Zealand (Dumbleton, 1963). In addition, two genera of the tribe Prosimuliini were reported: an unrevised "Cnephia" from Australia (9 spp.) and Sulcicnephia from Peninsular Malaysia. It should be remembered that the record of the latter genus was based on the tentative assignment of the unique species, i.e., Su. unidens, described from the pupa and larva, both of which have, though, many characters atypical for the genus Sulcicnephia mostly recorded from Central Asia (Takaoka and Davies, 1995). The male adult of Su. unidens recently obtained also differs in many morphological characters from most of the other Sulcicnephia species and presents more characters of tribe Simuliini than those of tribe Prosimuliini 


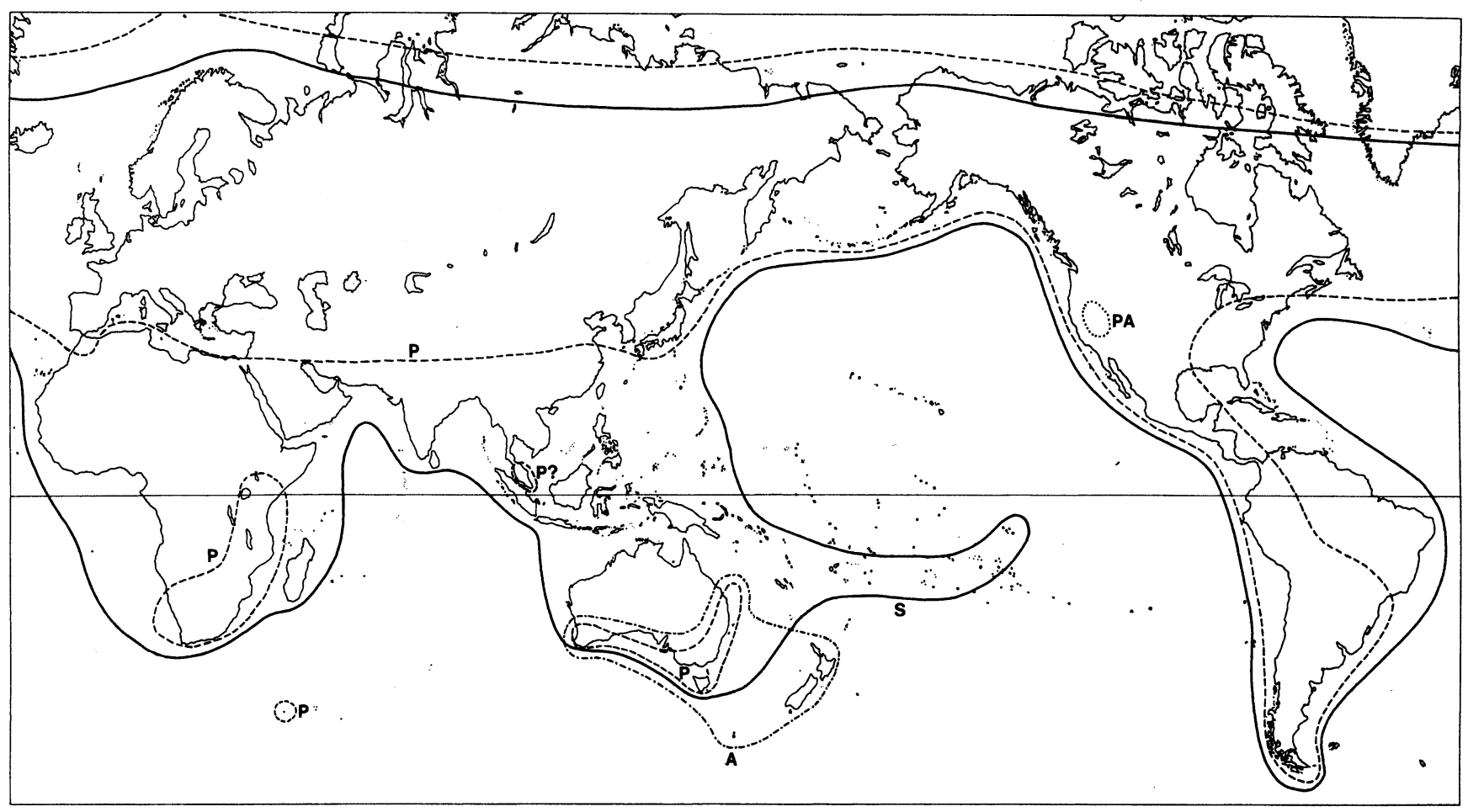

Figure 2 The world distributions of the supraspecific taxa of Simuliidae present in the Oriental and/or Australasian Regions. P, tribe Prosimuliini; S, genus Simulium s.l.; A, genus Austrosimulium; PA, subfamily Parasimuliinae (shown only for reference).

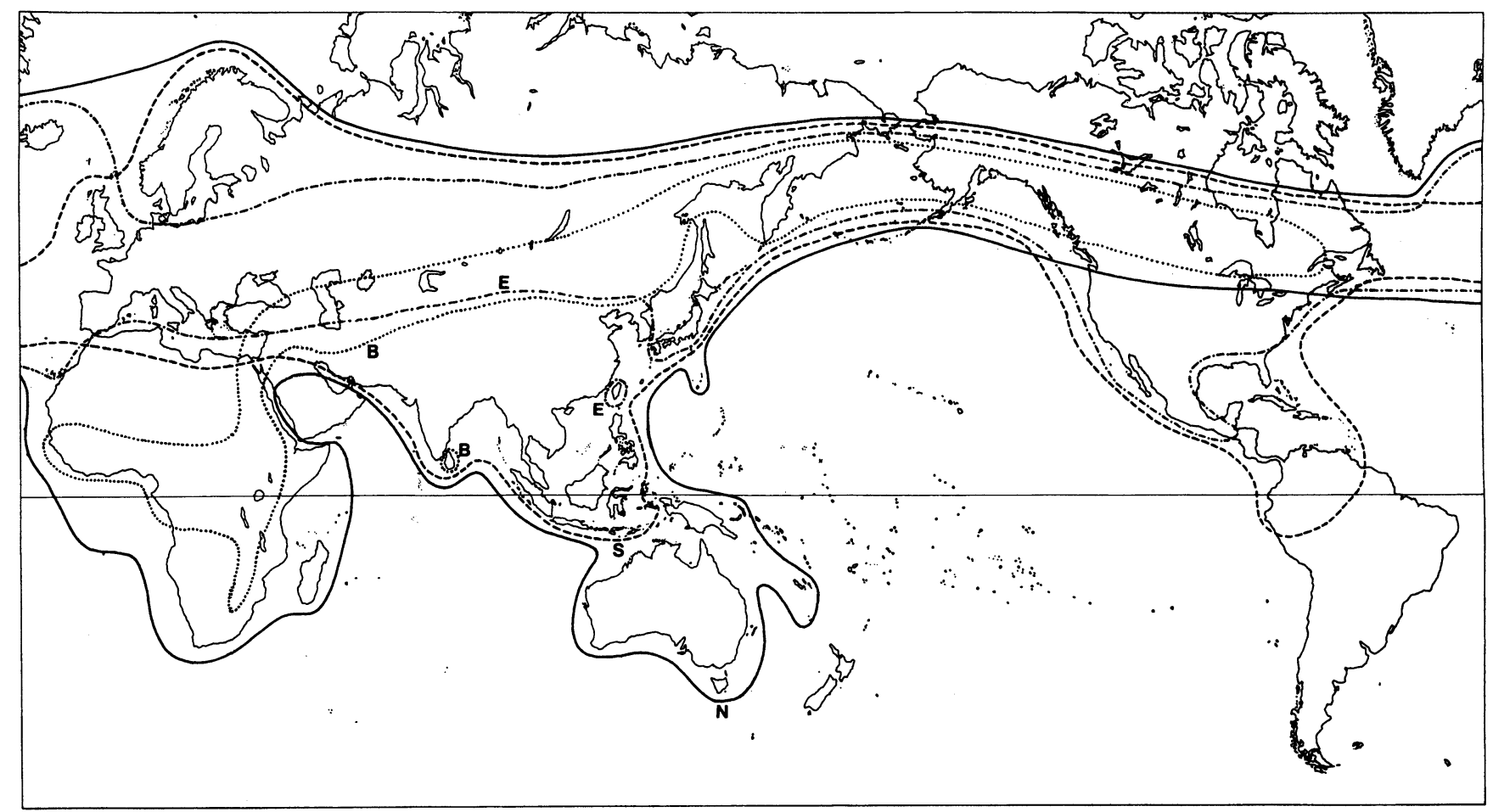

Figure 3 The distributions of four subgenera of Simulium s.l. in the Oriental and Australasian Regions. B, Byssodon; E, Eusimulium; N, Nevermannia; S, Simulium s.str. 


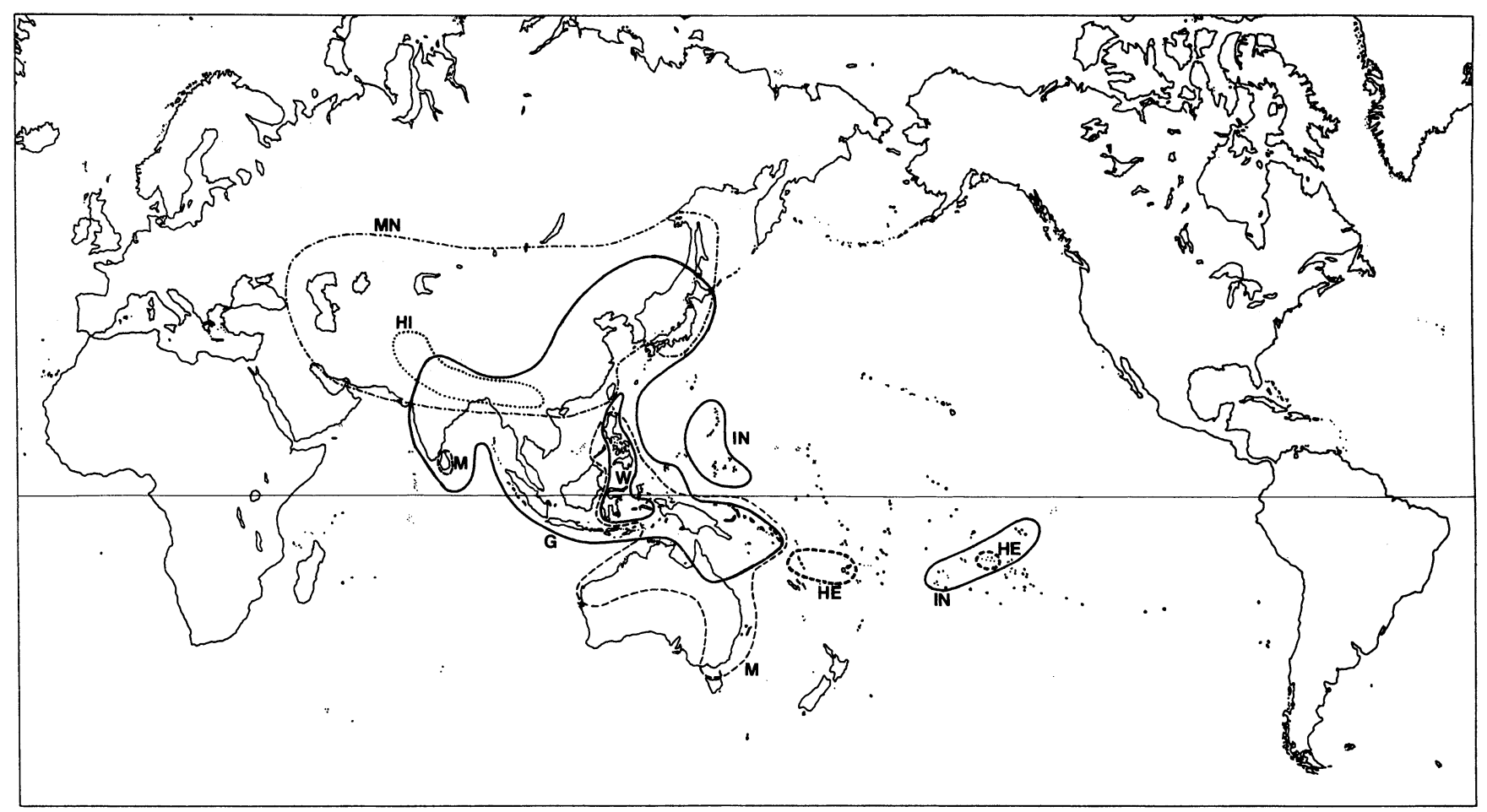

Figure 4 The distributions of seven subgenera of Simulium s.l. in the Oriental and Australasian Regions. HE, Hebridosimulium; HI, Himalayum; IN, Inseliellum; G, Gomphostilbia; M, Morops; MN, Montisimulium.

(unpublished data). Detailed taxonomic studies in future are certainly needed to prove that Su. unidens is assignable to the genus Sulcicnephia and also to the tribe Prosimuliini.

\section{DISTRIBUTION OF GENUS SIMULIUM S.L.}

IIa. Distributions at subgenus level (Figs. $3 \& 4$ )

The Simulium fauna of these regions is represented by five main subgenera, Gomphostilbia, Inseliellum, Morops Enderlein, Nevermannia Enderlein and Simulium s.str. All but Inseliellum probably are not monophyletic, including certain heterogenous speciesgroups. There are six other minor subgenera of Simulium s.l. Four subgenera, i.e., Nevermannia, Simulium s.str., Eusimulium Roubaud and Byssodon Enderlein, are all cosmopolitan, of which first two occur widely in the Asiatic continent and extend eastwards to cross both the Wallace's and Weber's Lines as far as Norfork Island and the Maluku Islands, respectively, while the other two, Eusimulium and Byssodon, are poorly represented by two species, each in Taiwan and Shimokoshiki Island of the Ryukyu Islands, and by one species in Sri Lanka, respectively (Fig. 3). The remaining seven subgenera except Montisimulium Rubtsov (3 spp.) are almost endemic to this area, and all but Himalayum Lewis (2 spp.) occur for the most part on the islands (Fig. 4). Gomphostilbia, one of the dominant subgenera (64 spp.), occurs in vast areas of the Oriental Region and extends northward to Japan and eastward to the Solomon Islands; it is also represented in the Palau Islands (1 sp.), in Papua New Guinea (9 spp.) and in northern Australia (1 sp.). Morops centers on Papua New Guinea (33 spp.) and the Solomon Islands (14 spp.), and extends southwards into Australia (8 spp.) and westwards through the Maluku Islands (7 spp.) into north Sulawesi (1 sp.) and the Philippines ( 8 spp.); Sri Lanka has one representative. One Malaysian species was tentatively placed in the subgenus Morops (i.e., S. (M.) gombakense) by Takaoka and Davies (1995), but this was recently proved to belong to the subgenus Gomphostilbia on the basis of the adult morphology (unpublished data). Inseliellum occurs on the Polynesian Islands (23 spp.) with its western outposts in Guam Island (2 spp.) and Truk Island (1 sp.) of Micronesia. Hebridosimulium Grenier and Rageau, a small subgenus (3 spp.) endemic to South Pacific, has also a disjunct distribution (1 sp. each in Fiji, Vanuatu and Society Islands). Wallacellum Takaoka, close to Morops, has its main range in the Philippines (8 spp.) but extends northward up to Yonakuni Island (1 sp.) of the Ryukyus through Lan-yu Island (1 sp.), east 


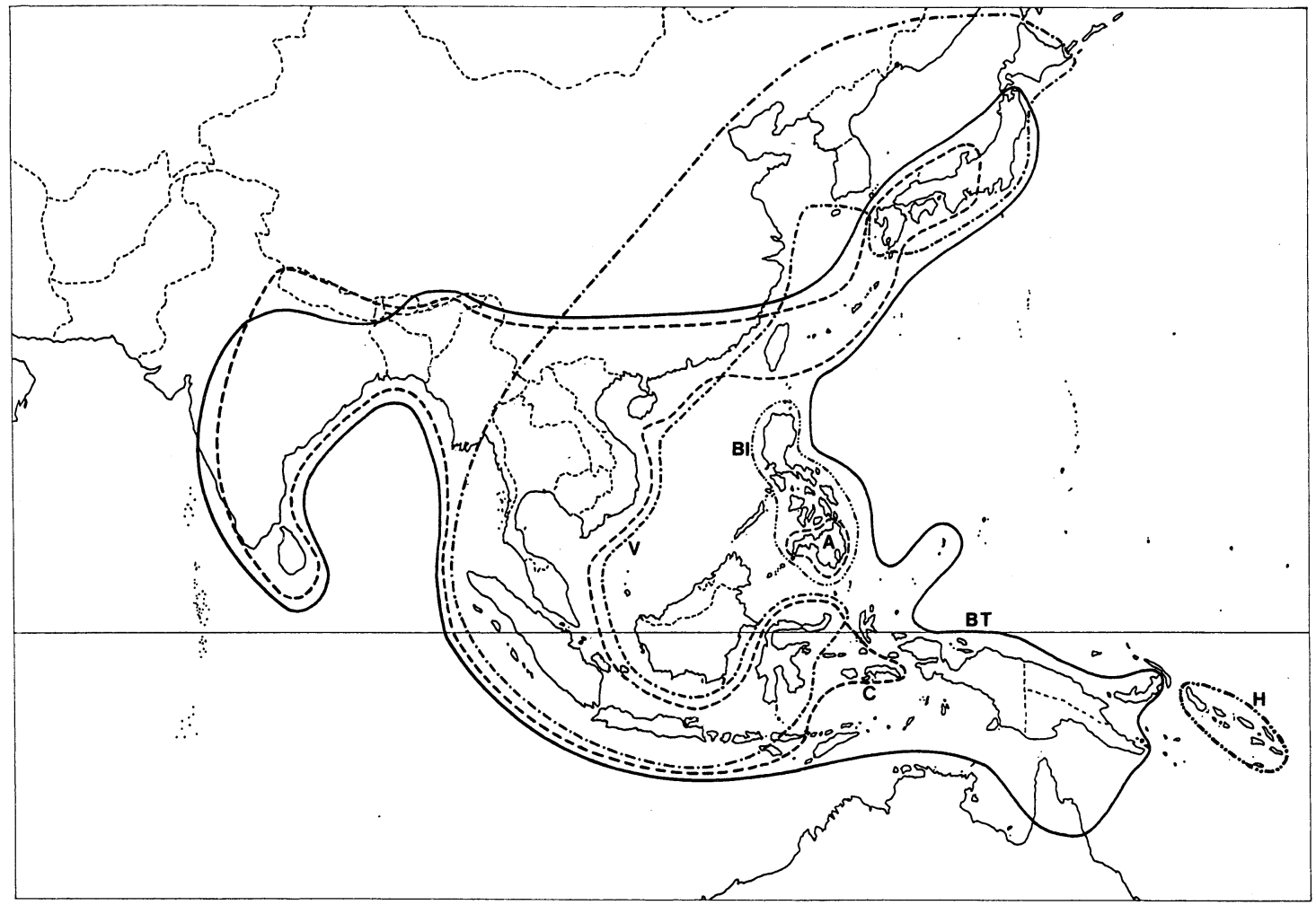

Figure 5 The distributions of six species-groups of the subgenus Gomphostilbia. A, ambigensgroup; BI, baisasae-group; BT, batoense-group; C, ceylonicum-group; H, hiroshii-group; $\mathrm{V}$, varicorne-group.

of Taiwan, and southward to Sulawesi Island (1 sp.); it is also represented in Seram Island (Ceram) (1 sp.) and Biak Island (1 sp.) (unpublished data).

\section{IIb. Distributions at species-group level}

\section{IIb-1. Subgenus Gomphostilbia (Fig. 5)}

There are five species-groups included so far in Gomphostilbia (Takaoka and Davies, 1996). Among these, three species-groups, i.e., batoense-, ceylonicumand varicorne-groups, have a wide range in the Oriental Region, and are extending their northeast range up to Japan; while in Irian Jaya, Papua New Guinea and north Australia only batoense-group is represented by four, nine and one species, respectively. Seram Island of the Maluku Islands and Flores Island of the Lesser Sunda Islands each have one species of the ceylonicum-group, as well as one and two species of the batoense-group (unpublished data). The two other minor speciesgroups, i.e., ambigens-group (1 sp.) and baisasae-group (3 spp.), are confined to the Philippines.

In the map (Fig. 5), one more species-group, hiroshii-group, was added. This is provisionally proposed to accommodate $S$. (G.) hiroshii recently found in the Solomon Islands and Bougainville Island (Takaoka,
1994, 1995). The last three species-groups constitute a different element, presenting several characters which are atypical among Gomphostilbia (Takaoka, 1983, 1994). In particular $S$. (G.) hiroshii is an enigmatic species, of which the male genitalia are typical for Morops, and the female genitalia (including the spermatheca with internal setae) are very similar to those of the ambigens- and baisasae-groups.

\section{IIb-2. Subgenus Morops (Fig. 6)}

Of the eight species-groups of Morops defined by Crosskey (1967) and Colbo (1976), two species-group, i.e., farciminis-group (8 spp.) and oculatum-group (7 spp.), are confined to Irian Jaya and Papua New Guinea; another species-group, papuense-group (1 sp.), is also distributed in Irian Jaya and Papua New Guinea but extends eastwards into the Solomon Islands and westwards as far as Seram Island; a similar pattern is shown for the clathrinum-group (ca. $20 \mathrm{spp}$.) which has, though, a weak representation in north Australia (1 sp.) and extends a little further westward as far as Halmahera Island. On the other hand three small groups, i.e., faheyi-group (3 spp.), lawnhillense-group (1 sp.) and mackerrasorum-group (1 sp.), have their limited distri- 


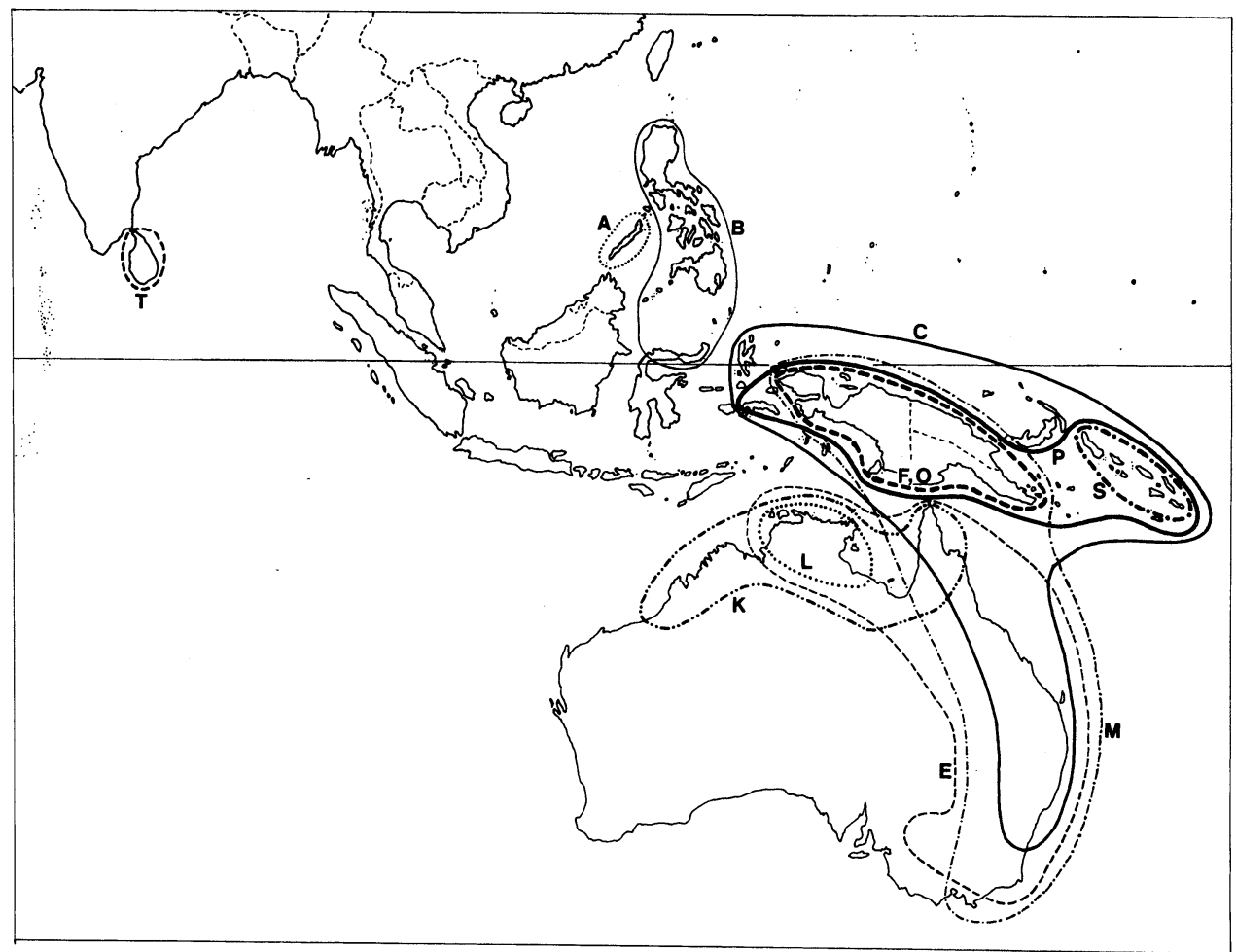

Figure 6 The distributions of 12 species-groups of the subgenus Morops. A, alienigenum-group (provisional name); B, banauense-group (provisional name); C, clathrinum-group; E, faheyi-group; F, farciminis-group; K, mackerrasorum-group; L, lawnhillense-group; M, melatum-group; O, oculatum-group; P, papuense-group; S, sherwoodi-group; T, trirugosum-group (provisional name).

bution only in Australia. The melatum-group (7 spp.) occurs in both Papua New Guinea (also Irian Jaya) and Australia although it is more abundant in Papua New Guinea.

The sherwoodi-group ( $6 \mathrm{spp}$.), recently proposed by Takaoka (1995), is limited to the Solomon Islands and Bougainville Island. In the Oriental Region, eight and one Morops species were reported from the Philippines and Sulawesi, respectively, of which one (from Palawan Island) was placed in the alienigenum-group (provisional name) and the others were in the banauensegroup (provisional name); one more species found in Sri Lanka (Davies and Györkös, 1988) was also provisionally treated to represent the different group (trirugosum group) by itself. The last four species-groups possess the male genitalia with parameral hooks, which are atypical among Morops (Takaoka, 1983, 1995; Davies and Györkös, 1988).

\section{IIb-3. Subgenus Nevermannia (Fig. 7)}

There are three species-groups of Nevermannia in these regions, which are much different morphologically from each other. The vernum-group, of an apparently
Holarctic origin, is widely distributed in north India, Indochina, south China, and adjacent continental islands, such as Taiwan and Java (2 spp. each) and also occurs on the oceanic islands $(S$. $(N$.$) aberrans in north Luzon$ and $S$. (N.) bonninense in Hahajima Island of the Bonin Islands). The feuerborni-group is a small group comprising 12 species, of which 10 species are distributed in the Oriental Region, one species, $S$. (N.) sasai, is in the Palaearctic Region and one species, $S$. (N.) mie, is in both regions. In Southeast Asia, its range extends eastward to Bali Island (1 sp.), Sulawesi Island (1 sp.) and Mindanao Island (1 sp.). The ruficorne-group, which has a wide distribution in the Ethiopian, Palaearctic, Oriental and Australasian Regions, includes only six species in the latter two regions, of which $S$. $(N$.) aureohirtum and $S$. (N.) ornatipes, both autogenous in ovarian development (Hunter, 1977; Takaoka, 1989), are widely distributed in the Oriental and Australasian Regions, respectively. The ranges of both species are separated from each other by the strait between Irian Jaya and the Maluku Islands, though in the latter islands only Halmahera is inhabited by $S$. $(N$.) aureohirtum; this species also exists in Flores Island of the Lesser 


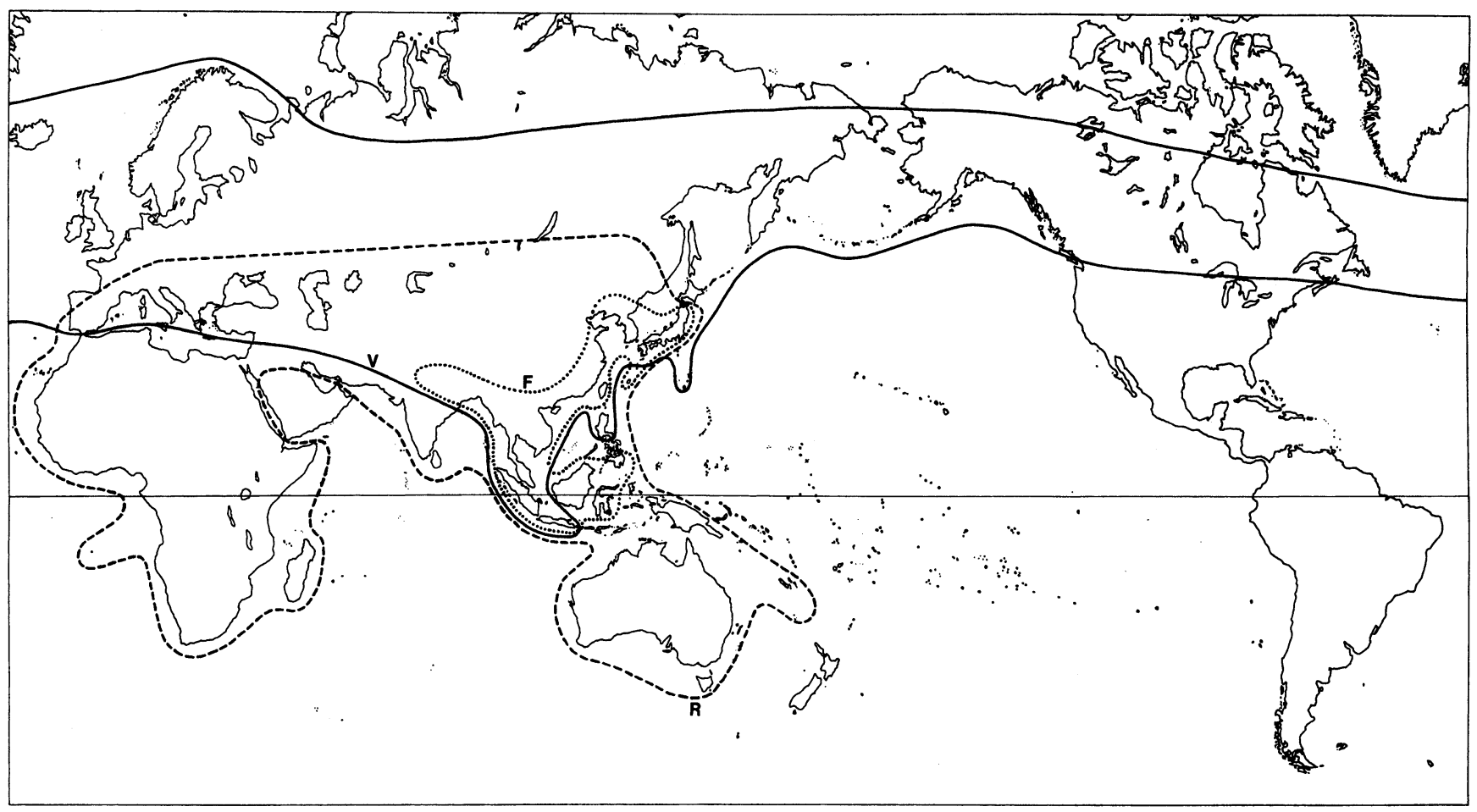

Figure 7 The distributions of three species-groups of the subgenus Nevermannia. F, feuerbornigroup; R, ruficorne-group; V, vernum-group (not confirmed from Sumatra, though included).

Sunda Islands (unpublished data). The other four species of the ruficorne-group have a restricted range: $S$. $(N$.$) angustitarse in south China, S .(N$.$) glatthaari in$ Sumatra, $S$. ( $N$.) neornatipes in New Caledonia, and $S$. $(N$.) norfolkense in Norfolk Island.

\section{IIb-4. Subgenus Simulium s.str. (Figs. 8, 9 \& 10)}

Twelve species-groups of the subgenus Simulium s. str. are known in the Oriental Region but not in the Australasian Region except one species of the melanopus-group recorded from Seram of the Maluku Islands (unpublished data), just east of Weber's Line redrawn in 1904. The tuberosum- and malyschevigroups are generally distributed in the Holarctic Region (Fig. 8). The malyschevi-group is represented by three species in south China, one of which occurs also in northeast India. The tuberosum-group (13 spp.) is widely distributed not only in the Asiatic mainland but also in the continental islands, such as Sumatra (2 spp.), Java (1 sp.), Borneo (2 spp.), Palawan Island (1 sp.) and the Ryukyu Islands (1 sp.). The ornatum- and variegatum-groups, which are morphologically very close to each other, are widely distributed in the Palaearctic Region, of which the ornatum-group has only two species in the Oriental Region, one in south China and the other in northwest India; on the other hand, the variegatum-group has a wide range mostly in the mainland of the Oriental Region, where it is represented by 13 species (Fig. 8).

The three species-groups, i.e., griseifrons-group (9 spp.), striatum-group (14 spp.) and multistriatum-group (9 spp.), which are apparently allied to one another, are widely distributed in the mainland and adjoining continental islands of the Oriental Region (Fig. 9), of which the griseifrons- and striatum-groups are spreading both northeastwards and northwestwards into the Palaearctic Region. The multistriatum-group extends only northwestwards into Central Asia. Both the multistriatum- and striatum-groups are well represented in India by five and six species, respectively.

All the other five species-groups have their ranges only on the islands except the nobile-group, which, in addition to its probable distribution center on the Philippines ( $6 \mathrm{spp}$.), is also represented by two species in the Asiatic mainland ( $1 \mathrm{sp}$. in northeast India and $1 \mathrm{sp}$. from northeast India to south China through Thailand), and also by one species in Taiwan (Fig. 10). The melanopus-group is mostly distributed in the Philippines (14 spp.); it is also represented in Sulawesi (4 spp.), Borneo (3 spp.), Peninsular Malaysia (1 sp.), and the 


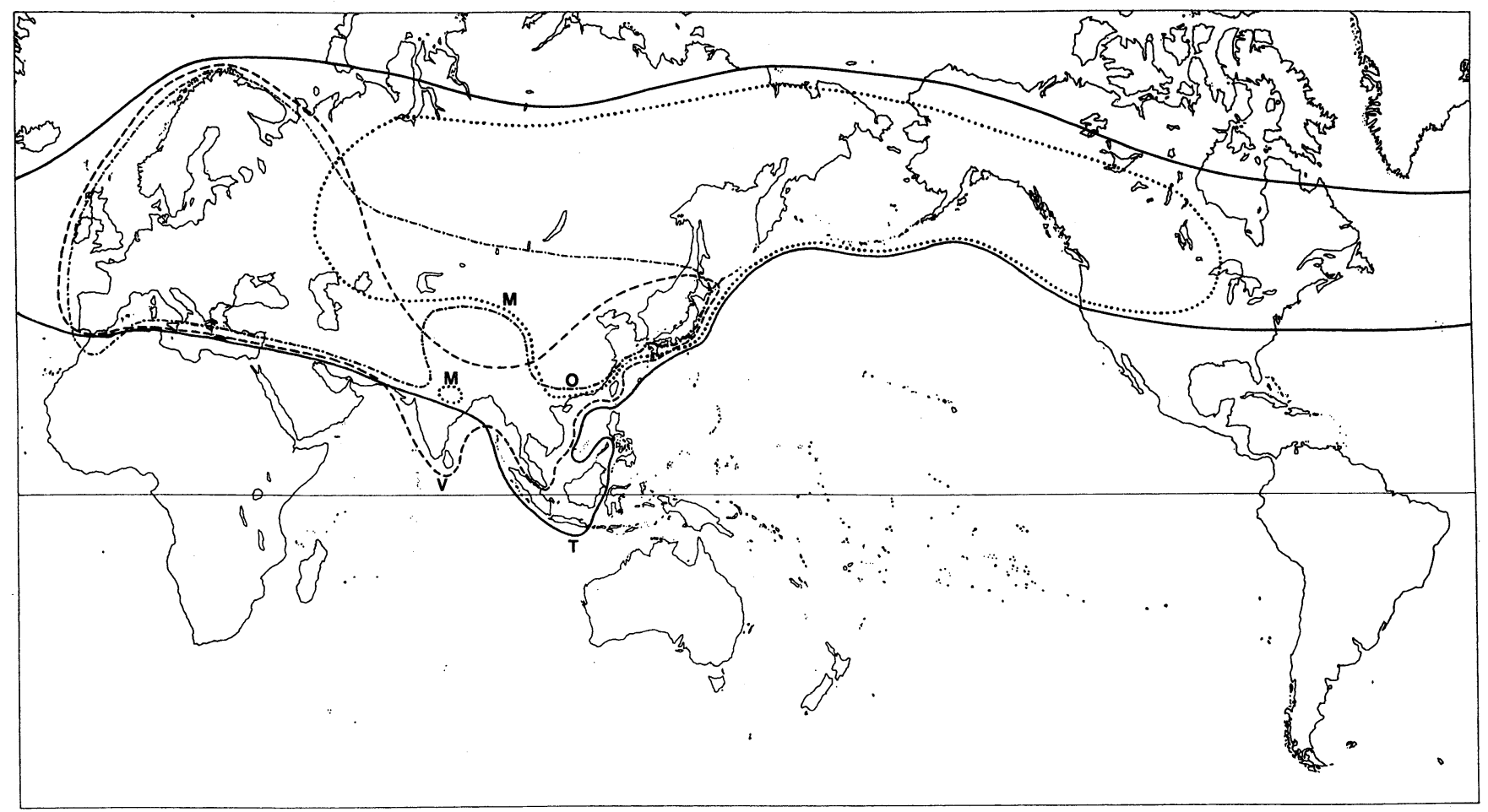

Figure 8 The distributions of four species-groups of the subgenus Simulium s.str. M, malyschevigroup; O, ornatum-group; T, tuberosum-group; V, variegatum-group.

Sunda Islands from Sumatra to Flores (3 spp.). The one undescribed species of this species-group was found on Seram Island of the Maluku Islands, representing the easternmost distribution of the subgenus Simulium s. str., as already noted. In the Sunda Islands (Sumatra, Java and Flores) there are two small species-groups, i.e., eximium-group (3 spp.) and celsum-group (provisional name, $2 \mathrm{spp}$.). The most striking finding is the new species-group (yet unnamed) found only on Sulawesi Island, which consists of 11 new species (unpublished data).

\section{SUMMARIZED DISTRIBUTION PATTERNS AND POSSIBLE DISPERSAL ROUTES OF SOME SUBGENERA AND SPECIES-GROUPS}

As shown in Figs. 2-4, the genus Simulium s.l. as a whole showed a rather simple pattern of distribution, with more subgenera in the Asiatic mainland, progressively diminishing its faunal variety toward the east to the South Pacific, reflecting the geographical situations. The similar tendency was already reported in many other groups of insects (Gressitt, 1961).

The more definite patterns of distribution were demonstrated at the subgenus and species-group levels. The 11 subgenera of the genus Simulium s.l. recorded in these regions are divided into five groups on the basis of their distribution patterns: the first group is an essentially Holarctic or Palaearctic, apparently is penetrating to varying extents from the north to the Oriental Region (eg., Eusimulium, Byssodon and Montisimulium, all confined to the mainland or nearby continental islands), and further extending their eastward ranges up to the Australasian Region (Simulium s.str. and Nevermannia); the second is confined to the Asiatic mainland (Himalayum); the third has its distribution center on the continental islands (eg., the Sunda Islands) and is widely extending northwards into the Asiatic mainland and eastwards beyond the Weber's Line (Gomphostilbia); the fourth is almost the same as the third except its distribution center on New Guinea and its westward and southward dispersals (Morops); the fifth is characterized by an exclusively insular distribution (Wallacellum, Inseliellum and Hebridosimulium). The last five subgenera are morphologically similar to one another, and certainly must have derived from a common ancestor, but their phylogenetic relationship has not been elucidated yet. None of the subgenera has been attempted to reconstruct its phylogeny, except Inseliellum which is presently under study by Dr. D. A. Craig (pers. commun.). 


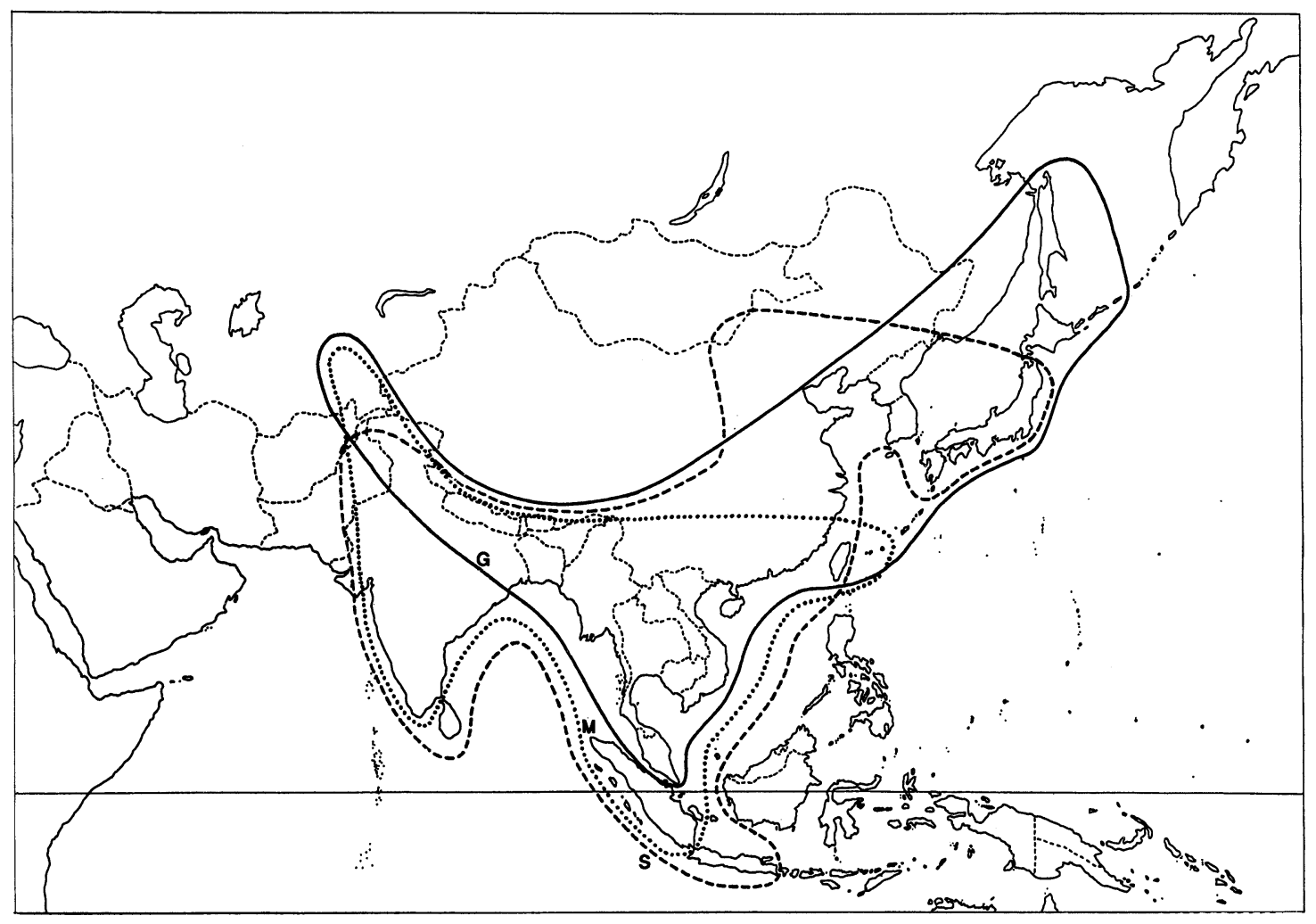

Figure 9 The distributions of three species-groups of the subgenus Simulium s.str. G, griseifronsgroup; M, multistriatum-group; S, striatum-group.

The subgenus Simulium s.str., though generally regarded as a cosmopolitan, is heterogenous in element, including eight species-groups whose ranges are mostly in the Oriental mainland and/or islands. They also exhibit two different distribution patterns, i.e., center of distribution being on the continent and/or continental islands in one group (eg., griseifrons, multistriatum, striatum, eximium, and celsum), and on the oceanic islands in the other (nobile, melanopus, and the unnamed group on Sulawesi). All these species-groups apparently had developed in tropical Asia. The first group may be inferred to have been inferior to the second group in over-sea dispersal abilities or in adaptabilities to insular environments. In the second group, supposedly the local speciation of the nobile-group had taken place on each island of the Philippine Archipelago and a few of its descendants had then undergone their westward and northward movements to reach northeast India, south China and Taiwan. This hypothesis on dispersal may be supported by the morphological characters, such as the variation in number and shape of the pupal gill filaments in the nobile-group, assuming that the pupal gill filaments tend to decrease in number and to become inflat- ed in the process of the specialization. The similar dispersal from the Philippines might have been done also by the melanopus-group, according to the morphological changes in the female genitalia, particularly, in the paraprocts (Takaoka, 1983). The unnamed speciesgroup found in Sulawesi is different from the former two species-groups by presenting a remarkable intraisland speciation.

The difference in colonization of oceanic islands by these species-groups (also by the three insular subgenera) may have been caused not only by the difference in the over-sea dispersal abilities of the adults and the adaptabilities of the immature stages to the various insular environments but also by the difference in the time of their ancester's arrival(s) and various geological events on each island in the past.

Among the species-groups widely distributed in and outside the Oriental Region, the ruficorne-group of Nevermannia seems to have well conformed to warm climate conditions and also to very slow-flowing waters since it was often found to inhabit lowland ditches with the water temperature of $30{ }^{\circ} \mathrm{C}$ or more in paddy fields where no other black fly species usually could live 


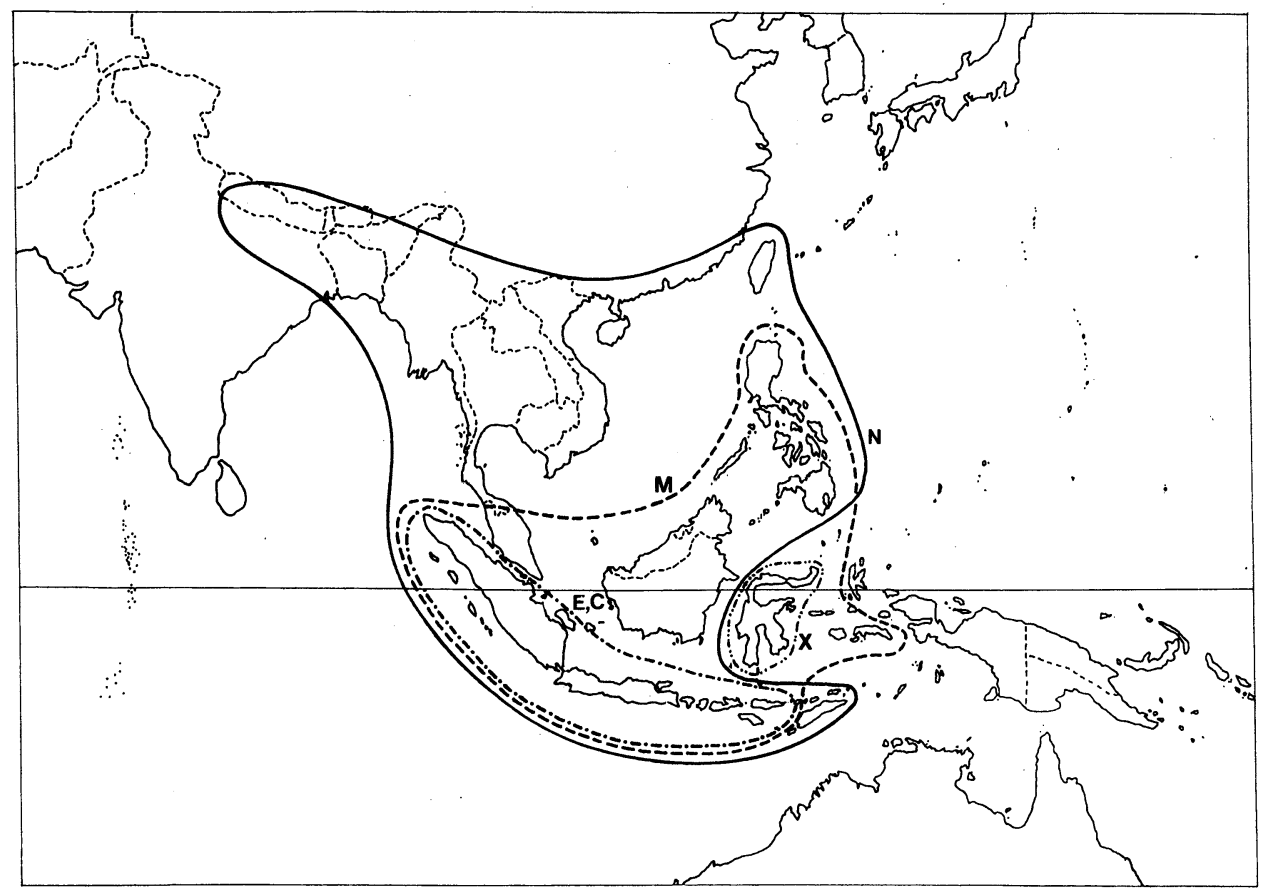

Figure 10 The distributions of five species-groups of the subgenus Simulium s.str. C, celsum-group (provisional name); E, eximium-group; M, melanopus-group; N, nobile-group; X, unnamed group.

(unpublished data). Interestingly $S$. (N.) glatthaari and $S$. (N.) aureohirtum in the Oriental Region have eight and six pupal gill filaments per side respectively, while all the other species in the Palaearctic, Ethiopian and Australasian Regions have four gill filaments. As inferred for the nobile-group, it may be speculated that the ruficorne-group had originated in Southeast Asia (probably in or near Sumatra) and had migrated both eastwards and westwards. On the other hand, the vernumgroup of Nevermannia inhabits only high mountains over $1000 \mathrm{~m}$ in altitude with cool climate conditions in Peninsular Malaysia, Java, Taiwan and Philippines (Takaoka and Davies, 1995, 1996; Takaoka, 1979, 1983). The relic distribution of this species-group may be explained by their influx into Southeast Asia from the north at the Pleistocene glaciations and their subsequent retreat northwards, leaving several species only at the high elevations where the climate was cool enough to support their breeding. This species-group would be predicted to be found also at the Mt. Kinabaru (alt., ca. $4100 \mathrm{~m}$ ) in north Borneo and at the Mt. Kerinci and others (alt., over $3000 \mathrm{~m}$ ) in Sumatra if explored.

The tuberosum-group of Simulium s. str., which seems to be less susceptible to the high temperature conditions, is distributed not only on the mainland but also on the continental islands, such as Sumatra, Java,
Borneo and Palawan, all of which are situated on the Sunda continental shelf delimited by the contour of 180 $\mathrm{m}$ below sea surface. The colonization of these islands in tropical Asia by this species-group might have occurred also during the Pleistocene glacial periods when these islands had been connected. The relatively poor representation on each continental island by these two species-groups, only one or two endemic species (Takaoka and Davies, 1995), might have been due to the shortage of time to allow subsequent local speciation.

\section{THE SIMULIUM FAUNA AND THE WAL- LACE'S AND WEBER'S LINES}

The Wallace's and Weber's Lines are the zoogeographical boundaries separating the Oriental from the Australasian Region. The significance of these lines differs by the different groups of animals (Mayr, 1944). The modified Wallace's Line (Huxley's Line) united by the Kano's Line coincides well with the western edge of the range of the insular subgenus Wallacellum (Figs. 1 \& 4), and the Wallace's Line 1910 corresponds to the eastern edge of the feuerborni-group range (Figs. 1 \& 7). However the more drastic change of the Simulium fauna is likely to be seen on both sides of the Weber's Line. In the Philippines the Oriental elements $(72 \%$ or 41 of 57 total spp., i.e., Nevermannia 4 spp., Gomphostil- 
bia 13 spp., and Simulium s.str. 24 spp.) outnumber the Australasian element (14\%, Morops 8 spp.) (Takaoka, 1983). The Sulawesi fauna of Simulium s. 1. is also characterized by the predominance of the Oriental elements $(92.8 \%$ or 26 of 28 total spp., i.e., Nevermannia 2 spp., Gomphostilbia 9 spp. and Simulium s. str. 15 spp.) and the impoverishment of the Australasian element (3.5\%, Morops 1 sp.) (Takaoka and Roberts 1988; unpublished data). The fauna of Flores Island of the Lesser Sunda Islands is all represented by the Oriental elements (Nevermannia 1 sp., Gomphostilbia 4 spp. and Simulium s.str. 3 spp.) (unpublished data). On the other hand, in the Maluku Islands, just east of the Weber's Line, the Australasian element ( $50 \%$ or 7 Morops spp. of 14 total spp.) somewhat predominates the Oriental elements (43\%, i.e., Nevermannia 1 sp., Gomphostilbia 4 spp., and Simulium s.str. 1 sp.) (unpublished data).

\section{ACKNOWLEDGEMENTS}

This study was in part supported by a Grant-in-Aid from the Japan Society for the Promotion of Science for Research Program in Malaysia in 1996, and from the Ministry of Education, Science and Culture, Japan for International Scientific Research Program in Indonesia from 1991 to 1994 (no. 030410653), and by the Indonesian Institute for Science (LIPI). I would like to thank Prof. I. Miyagi, representative of the above-mentioned research program supported by the Ministry of Education, Dr. K. Kamimura, Toyama Medical and Pharmaceutical University, Dr. M. Mogi, Saga Medical School, and Dr. T. Toma, Ryukyu University, for their help in the collection trips in Indonesia. My appreciation goes to Prof. S. H. Sigit, Bogor Agricultural University, Prof. Chairuddin Rasjad, Dr. K. G. Abadi, and Dr. Syafruddin, Hasanuddin University, and Prof. Yong Hoi Sen, University of Malaya, for their kind cooperation during my stays in Indonesia and Malaysia. Thanks are due to Ms C. Aoki, Oita Medical University, who kindly assisted in drawing maps.

\section{REFERENCES}

1) Colbo, M. H. 1976. Four new species of Simulium Latreille (Diptera: Simuliidae) from Australia. J. Aust. Ent. Soc., 15, 253-269

2 ) Craig, D. A. 1983. Phylogenetic problems in Polynesian Simuliidae (Diptera: Culicomorpha): a progress report. GeoJournal, 7, 533-541

3 ) Craig, D. A. 1987. A taxonomic account of the black flies (Diptera: Simuliidae) of the Society Islands-Tahiti,
Moorea and Raiatea. Quaest. Entomol., 23, 372-429

4 ) Craig, D. A. and Craig, R. E. G. 1986. Simuliidae (Diptera: Culicomorpha) of Rarotonga, Cook Islands, South Pacific. N.Z. J. Zool., 13, 357-366

5 ) Craig, D. A., Fossati, O. and Séchan, Y. 1995. Black flies (Diptera: Simuliidae) of the Marquesas Islands, French Polynesia: redescriptions and new species. Can. J. Zool., 73, $775-800$

6 ) Crosskey, R. W. 1967. The classification of Simulium Latreille (Diptera: Simuliidae) from Australia, New Guinea and the Western Pacific. J. Nat. Hist., 1, 23-51

7 ) Crosskey, R. W. 1988. Annotated checklist of the world black flies (Diptera: Simuliidae). In Black flies: ecology, population management, and annotated world list. Edited by K. C. Kim and R. W. Merritt. Pennsylvania State University Press, University Park, pp. 425-520

8 ) Crosskey, R. W. 1989. Family Simuliidae. In Catalog of the Diptera of the Australasian and Oceanian regions. Edited by N. Evenhuis and E. J. Brill. Bishop Mus. Spec. Publ., No. 86, pp. 221-225

$9)$ Crosskey, R. W. 1990. The Natural History of Blackflies. Chichester, John Wiley, ix + 711pp.

10) Datta, M. 1983. A review of the Simuliidae (Diptera) from the Oriental Region. Orient. Insects, 17, 215-267

11) Davies, D. M. and H. Györkös. 1988. The Simuliidae (Diptera) of Sri Lanka. Description of a new species of Simulium (Morops). Can. J. Zool., 66, 605-610

12) Dumbleton, L. J. 1963. The classification and distribution of the Simuliidae (Diptera) with particular reference to the genus Austrosimulium. N.Z. J. Sci., 6, 320-357

13) Gressitt, J. L. 1956. Some distribution patterns of Pacific Island faunae. Syst. Zool., 5, 11-47

14) Gressitt, J. L. 1961. Problems in the zoogeography of Pacific and Antarctic Insects. Pacific Insects Monograph 2, 1-94

15) Hunter, D. M. 1977. Sugar-feeding in some Queensland black flies (Diptera: Simuliidae). J. Med. Entomol., 14, 229-232

16) Mayr, E. 1944. Wallace's line in the light of recent zoogeographical studies. Quart. Rev. Biol., 19, 1-14

17) Takaoka, H. 1979. The black flies of Taiwan (Diptera: Simuliidae). Pacific Insects, 20, 365-403

18) Takaoka, H. 1983. The blackflies (Diptera: Simuliidae) of the Philippines. Japan Society for the Promotion of Science, Tokyo, xi +199 pp.

19) Takaoka, H. 1989. Further observations on the autogeny of Simulium aureohirtum Brunetti (Diptera: Simuliidae) in the Ryukyu Islands. Jpn. J. Sanit. Zool., 40, 21-28

20) Takaoka, H. 1994. A new blackfly species of Simulium (Gomphostilbia) from Solomon Islands, South Pacific (Diptera: Simuliidae). Jpn. J. Trop. Med. Hyg., 22, 103108

21) Takaoka, H. 1995. The Simuliidae (Diptera) from the Bougainville Island, Papua New Guinea. Jpn. J. Trop. Med. Hyg., 23, 239-252

22) Takaoka, H. and Davies, D. M. 1995. The black flies (Diptera: Simuliidae) of West Malaysia. Kyushu Univer- 
sity Press, Fukuoka, vi +175 pp.

23) Takaoka, H. and Davies, D. M. 1996. The black flies (Diptera: Simuliidae) of Java, Indonesia. Bishop Mus. Entomol. Monograph (in press).

24) Takaoka, H. and Roberts, D. M. 1988. Notes on black- flies (Diptera: Simuliidae) from Sulawesi, Indonesia. Jpn. J. Trop. Med. Hyg., 16, 191-219

25) Takaoka, H. and Suzuki, H. 1995. The Simuliidae (Diptera) from the Solomon Islands, South Pacific. Jpn. J. Trop. Med. Hyg., 23, 253-272 